\title{
Erratum to: Current advances in prenatal imaging of congenital diaphragmatic hernia
}

\author{
Beth M. Kline-Fath
}

Published online: 2 February 2012

(C) Springer-Verlag 2012

\section{Erratum to: Pediatr Radiol}

\section{DOI 10.1007/s00247-011-2183-3}

The editors and publisher regret that this article was inadvertently published with the wrong title, "Congenital diaphragmatic hernia," and apologize to the author for the oversight. The correct title is given above.

In addition, a corrected version of Table 2 is presented.
Table 2 Prognostic indicators for MRI and US

\section{Markers of poor prognosis}

Additional anomalies

Bilateral

Liver up

Stomach up

US tools

Pulmonary hypoplasia

LHR

O/E LHR

3D US

Pulmonary hypertension

Pulmonary artery Modified McGoon

Pulmonary artery Doppler PI or PEDRF
Diagnosis before 25 weeks

Polyhydramnios

Hydrops

Left ventricular hypoplasia

MRI tools

Pulmonary hypoplasia

Lung signal intensity

Absolute FLV

RFLV or o/eFLV

PPLV

Late gestation FLV

Pulmonary hypertension

Modified McGoon index

Diffusion

The online version of the original article can be found at http://dx.doi. org/10.1007/s00247-011-2183-3.

\section{B. M. Kline-Fath}

Department of Radiology, Fetal Care Center of Cincinnati,

Cincinnati Children's Hospital Medical Center,

Cincinnati, $\mathrm{OH}$, USA

B. M. Kline-Fath $(\square)$

Department of Radiology, MLC 5031, Cincinnati Children's,

Hospital Medical Center,

3333 Burnet Ave.,

Cincinnati, OH 45229, USA

e-mail: beth.kline-fath@cchmc.org 